\title{
Review of: "Beyond livestock carrying capacity in the Sahelian and Sudanian zones of West Africa"
}

\author{
Mehdi Saqalli ${ }^{1}$ \\ 1 Université de Toulouse-le-Mirail (Toulouse II)
}

Potential competing interests: The author(s) declared that no potential competing interests exist.

\section{Beyond livestock carrying capacity in the Sahelian and Sudanian zones of West Africa} This is a remote sensing and modelling study over a portion of Sahel centered on Burkina Faso and surroundings.

A first premise is surprising, the idea of a structural need for supplemented feed for livestock keepers in the area: it does exist but considering the economic strength of a smallholder as the main criterion for buying it is far from local economic dynamics. Even more, envisioning terms such as "efficiency and profitability" of livestock production in Northern Sahel needs to redefine what efficiency is in the context. A second premise is the fact that ecosystems may be considered as natural while they are pastured for at least 2000 years. These are socio-ecosystems where all annual and multi-annual vegetal species were and are selected by grazing pressure, inducing quicker cycles, resilience and fast recovery facing grazing, etc. They are also adapted to rapid and dramatic changes in terms of rainfall productivity. The literature authors used focused on recent trends describing present changes as a shift from a balanced situation, while we have actually very little data over rainfall, variability, cycles and levels before 1910 (see Gado). Soil parameters are twice cited as possible biases without further explanations. Figure 1 rainfall data are in contradiction with the assertion regarding a drier Sudanian climate and a wetter Sahelian climate: no trend can be observed.

Formally, the materials and methods is not clear at all and is reduced to biases: It misses a table clearly describing each spatial layer used in the model and its spatial and temporal resolution: one should try to determine it during the results section, which itself describes methods. Biases are a result that should be discussed.

It helps me introduce here the most important criticism over this article:

The real potential value of pastoral land is linked to the temporary differences between territories, i.e the fact that the spatial variability of available biomass is different from a place to another during the rainy season. The temporal resolution of the model is here annual, while at least this should have been a minima the week or the $10^{\text {th }}$ day period several FEWS programs such as the Sim Bétail in Niger use in their pastoral previsions. Practically, one cannot see what sources and how they were used for assessing spatially the rainfall even at the annual mesh.

How were assessed spatially the demand? Because one may see on figure 2 below that trends are linked to 
national census (because you have border effect) but this is yet to be justified. The FAO 2010 census is solely indicatory as it is impossible that such herds do not move. One may suggest:

- For defining the demand for each year to integrate the trends already defined and apply it uniformly to each pixel, improving thereby the annual resolution of this demand.

- Create a cellular automata starting in 2010 and allowing the livestock charge flowing from pixels to pixels attracted by favorable pixels (with random directions when attractions are equivalent) showing by then the very structural and somehow unavoidable transhumance. Indeed, the modelled area does not include the pastoral area where remains only pastoral Fulani activities and where a large part of the herd flee for grazing here and by then free the cropped areas. Even more, one may suggest to map the areas where farmers agree to let herds graze fields after harvests and areas where they do not (center of Ghana or Benin for instance), meaning cutting this source of feed off

- Using WorldClim providing past rainfall and temperature, determine the value of the biomass for each month and then only for shifting from annual to monthly resolution

Yes, this gap is acknowledged in conclusion but this omission is so enormous that all the results are not justifiable : one may name the article "Beyond livestock transhumance" because you show how the transhumance is necessary. The article assess the fact that transhumance occurs and creates conflicts but it is also due to the expansion of cropped surfaces. There is no figure S5 and one may not see the relation between degraded lands and LCC. It is even dangerous to assess such assertions because one may often see structurally poor lands (especially in lateritic plateaus of the Continental Terminal in Niger or the northern granitic block between Dori and Tera) as "degraded". One may then suggest to use the results you provide and change totally the purpose of the article by focusing on this main lack and show ab absurdo that transhumance did save livestock herders along the period you study

The conclusion is very unclear: beyond the "positive" trend describing a crisis, one may suggest to check all superfluous or missing " $\mathrm{s}$ " (an increase, but it decreases). There is no connexion between this conclusion and the title which seems here false. Development conclusions are hazardous when proposing new (and therefore, at least manpower-costly) technologies for dealing with the climate crisis to come. Economic policy (for instance supporting the price of products that imply a reduction of the livestock and an increase of its quality, such as dairy products) is far more justifiable. Finally Early warning systems already exist since at least 2001 but they are hardly listened (see various articles on the famine of 2005 in Niger).

As a result, the article "Beyond livestock carrying capacity in the Sahelian and Sudanian zones of West Africa" is twice false: it is not beyond but strictly a balance between a quite good but temporally inadequate offer a totally artificial demand. Then this miss transhumance because of this inadequate temporal resolution. It may be renamed for "The value of transhumance: showing ab absurdo the crisis of livestock carrying capacity in the Sahelian and Sudanian zones of West Africa". 
